\title{
Updating the Spatial \\ Figures of Learning
}

\section{BARBARA COPPETTI}

Polytechnic of Milan, Department of Architecture and Urban Studies 
The educational institution represents the basis of civil society: any great empire or civilzation began to be considered when it developed a structured educational system capable to educate aware citizens participating in public life. Retracing the etymological origin of hte term school, the latter suggests a hidden component which should still be at the basis of the idea of contemporary school. The word comes from the Latin schola, which derives from the ancient Greek scholè that means to take care of free time. The scholè was the time in which one rested form the effort of daily life, to devote himself to study and reasoning. The proposal in this paper is that the first hidden layer of architectural education is to give back to the school its authentic meaning of scholè, place of the otium, where the love of knowledge lives. The Place on one side and the Educator on the other are the first components to update our universities: open campus, informal spaces, off-the-record paths + innovative teaching are the main tools to pursue a better quality of architectural education.

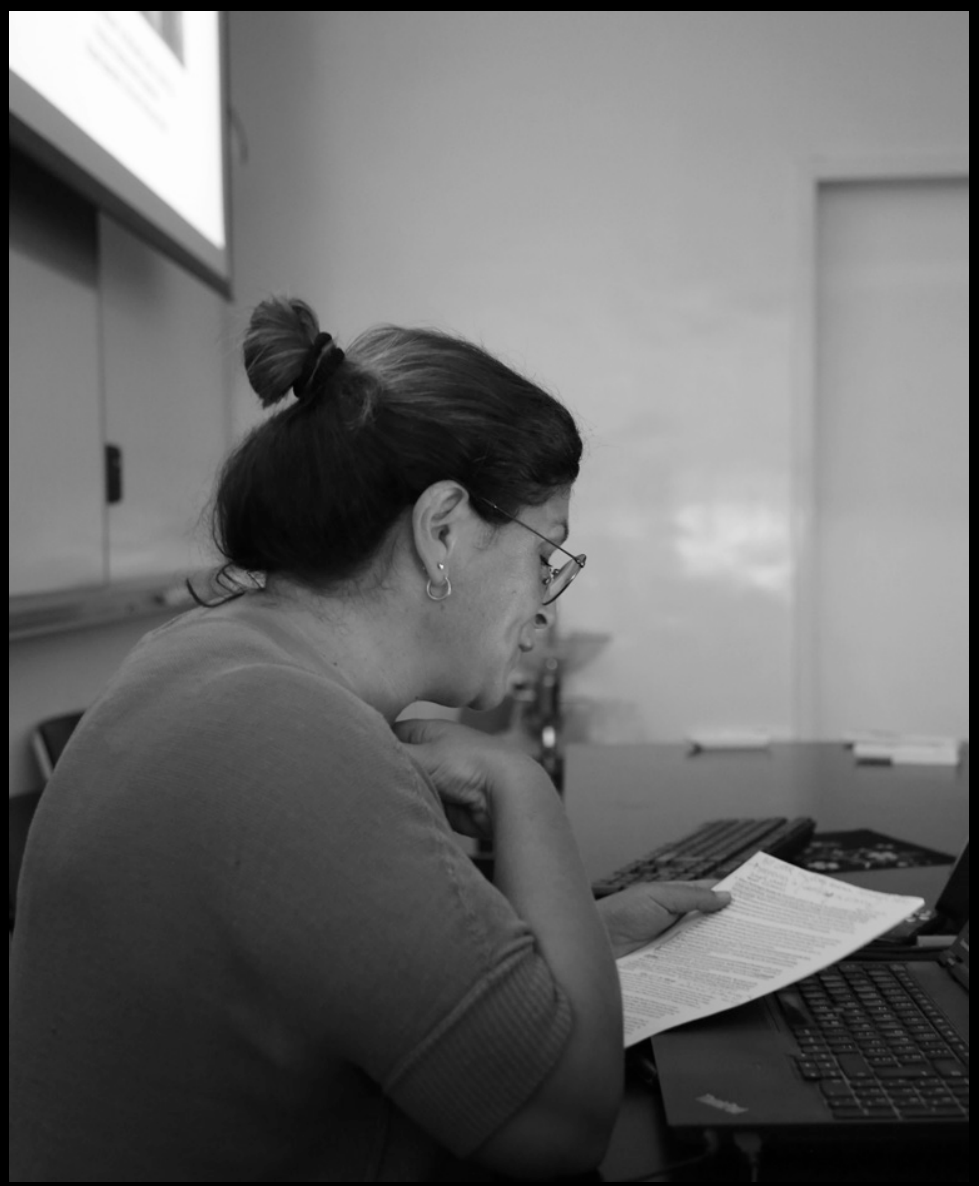


Schools, fundamental institutions in civil society, are advancing and experimenting with new educational models at all levels with the aim of making them a place of life, an environment for learning which is open to the varying didactic approaches and rapid changes of recent decades. University education, but not only, must be innovated to cater for and better promote personal and diverse development processes so that everyone can receive support and nurture their own specific abilities.

Flexibility and dynamism are the cornerstones of the new didactic approach, taking the place of the passiveness, coercion and imposition so prevalent in the theoretical and detached educational models that have now been completely superseded.

Emphasising the close connection between architecture and pedagogy, common economic, environmental, social and educational problems underline the urgent need to modernise school buildings and university campuses. This need for change involves the key structures; from the concept of hosting students and the entire educational community to questions connected with energy performance, better and reduced environmental impacts, the modernisation of materials and technologies. Campuses, as hubs of excellence, and schools, as public community buildings, should identify themselves as new institutions that are recognisable in the local context of the neighbourhood, the urban fabric and the city, but also at global level in terms of comparison with other institutions.

An ongoing phenomenon is certainly the stimulus for modernisation in terms of internationalisation and social integration through inclusion policies and participation. At all levels of schooling, teaching spaces are subject in major European cities, to programmes for the replacement of obsolete school buildings, projects for the redevelopment and modernisation of facilities, and tenders for the designing of new school structures.

\section{ROOTS: PERIPATETIC SCHOOL AND PAIDÉIA IN CLASSI- CAL GREECE, SCHOLA AND OTIUM IN ANCIENT ROME}

As part of this reflection on the educational institute as the basis of civil society let me delve back into the past to identify the necessary foundations on which I base my argument. The great empires and civilisations in history only began to be considered as such after having developed a structured education system that was able to produce informed citizens capable of participating in public life. In my opinion there is a dimension in the etymology of the word school that should be present in the idea of the contemporary school. The word derives from the Latin schola, which in turn comes from the Greek scholè, which meant 'free time'. Scholè was the time in 
which one rested from the exertions of daily life and focused on studying, reasoning and thinking.

In the Lyceum, the great Greek school of philosophy founded by Aristotle, also known as the "peripatetic school" (Peripatetiké Scholé in Greek), members would meet at the Gymnasium of Athens, close to the temple dedicated to Apollo Lyceus, and walk informally "peri", i.e. around the perimeter of the building surrounded by a colonnade, conversing with each other. During their walks, the members of Aristotle's school would embark on informal debates and philosophical and scientific dialogues while moving around from place to place, always in motion. A practice that fitted with the concept of dynamic learning, of learning during the act of walking together outdoors. The main contemporary theories and concepts of innovative didactics include a hypothesis analogous to that of Aristotle's peripatetics: the practice of learning through active, diligent and dynamic work that simultaneously involves both groups of teachers and learners.

The present crisis ${ }^{1}$ afflicting the school classroom, as the only place where teacher-led educational activities can take place, forces us to consider the value of experiencing places, spaces and their differences as a key aspect of education. Architects are taught that observation and experience inevitably imply the presence of a physical body: a body that measures the distance or proximity of things as well as the degree to which they change over time (at night and during the day, for example, or the differences in light depending on the seasons) ${ }^{2}$. As part of the work we carry out in the design workshops I have been holding for years, the Architecture Experiences class involves the planning of itineraries aimed at improving the programme of ex-cathedra lessons. Experiencing places enables students to gain knowledge of all of the scales of architecture and the landscape: from distant horizons to the local features of the overall architecture, to specific environments, materials and

1 Official Journal of the Italian Republic. Law 107 / July 13t, 2015, Reform of the School [main source: Gazzetta Ufficiale della Repubblica Italiana, Legge 107 del 13 luglio 2015, Riforma della Scuo/a]. The school system has been completely reformed, to guarantee autonomy for the purpose of a better training offer. The aim of the Reform is to affirm the central role of school in society, raise education levels and student skills, tackling socio-cultural inequalities, prevent and recover school dropout. Creating an open school as innovative research and teaching laboratory means proposing citizenship participation and education processes, to guarantee the right to study and equal opportunities.

2 B. Coppetti, "L'esperienza del passato prossimo" in "Imparare Architettura. I laboratori di progettazione e le pratiche di insegnamento" by J. Leveratto, Atti del VII Forum ProArch, Società Scientifica Nazionale dei docenti di Progettazione Architettonica, ISBN 978-88-909054-6-9 
details. Through a familiarisation process, the collective experience of architecture in the 20th century sought to construct a sphere of communicable meaning, knowledge that was lasting because it was direct; an awareness that would ideally form part of everybody's cultural baggage.

At the same time there was also the humble ambition of introducing the educational concept implied in the complex Ancient Greek term Paidéia. As well as teaching, Paidéia also implies the ethical and spiritual growth of children in order that they may become mature and fully-formed citizens. An elevated form of culture able to guide their harmonious integration in society, in a field of application whose disciplines, overseen by the Muses, included Art, understood as the all-pervading truth, elements of history, rhetoric, dance, religion and music (U. Galimberti). The education and human formation implied in Paidéia constituted the pedagogical model during the golden age of Athens in the 5 th century B.C., a time when the fruits of its continuous quest to achieve the ideal form of civilisation and morality that engaged man as a whole flourished.

Subsequently, the Roman word schola recognised the original idea of leisure, rest and time dedicated to growth, philosophical dialogue and science. In the first etymological dictionary of the Italian language, Ottorino Pianigiani ${ }^{3}$ proposes a connection between the original meaning of the term schola and the spaces around the baths of the Roman spa, called schola-labri and schola-alvei. These were areas where people could converse and share ideas as they waited their turn. In this context, traditional etymology, as well as a number of contemporary scholars ( $\mathrm{Te}$ nuta, 2013) ${ }^{4}$, draws a distinction between otium, the free time of privileged citizens who were able to dedicate themselves to their studies or to reflection, and negotium, the time spent taking care of the practical aspects of life and financial affairs. Otium was a moment connected with excellence and elevated lifestyles that formed part of the schola. However, over time the sense of dynamic learning implied by term was completely lost and it became associated with a motionless abstention from all activities, a habitual and self-indulgent form of laziness. I believe that we need to find a new sense of balance between the Roman otium and negotium because in the contemporary world we devote most of our time to neg-otium, i.e. negotiating, quantifying and evaluating all and sundry, including education and the results we expect. A misleading aspect because it

3 Etymological Vocabulary of the Italian Language by Ottorino Pianigiani, vol. 2, Rome-Milan 1907

4 http://www.edscuola.eu/wordpress/?p=34688 
forgets that the etymological root of neg-otium 'denies otium' and therefore denies the time dedicated to reflection, thought and the search for meaning implied in the Latin meaning of the term schola.

I want to nail down one other key moment in the ancient history of our schools, the point in time when the meaning of the term schola was definitively changed to refer to a specific place, to the school building constructed for educational and learning purposes. The Palatine school founded by Charlemagne was the first public school in the world. Charlemagne created a circle of intellectuals from all over the Carolingian Empire - those who had developed an innovative international atmosphere over the course of the 9th century - in a specific location. Charlemagne developed the meaning of school as an institution for moral and intellectual education, a school which, at the time, was unique in not being dependent on the ecclesiastical institutions. It was therefore the first public school free of ideological constraints. A major step towards the ambitious goal of uniting a huge empire consisting of many different populations.

\section{A COMMON PROJECT, ACTIVE LEARNING AND SHARED GOALS}

The common hypothesis that it is possible to see inside our schools and all levels of education stems from our need to develop a widespread ethical responsibility towards environmental issues connected with controlling resources. The commitments of the UN, the numerous protocols signed by many countries to protect the environment (the main ones including the 1997 Kyoto Protocol on global warming, drafted by around 180 countries across the world) and local actions to inform and raise awareness of the issue have, over time, led to the general acceptance that our resources are limited and that we need to monitor and reduce our consumption as a result. An awareness that involves individuals and the collective, that brings together educational communities and students in an effort to adopt a common and shared approach. An interdisciplinary issue that is shaping new forms of teaching, that involves all age groups, all educational institutions whether public or private, and that also specifically regards the discipline of architecture.

Inside the hidden layers of the School, as well as strengthening an overarching project that involves the environmental, social and economic sustainability of our existence in the world, I think we must also adopt an approach that regards students as an essential resource for the future. Students who are the main protagonists of their own education, thinkers and scholars that 
love knowledge, researchers in love with knowledge and fonts of energy, ideas and proposals. My Architecture Experiences class is creating key moments of across-the-board action: the students react to stimuli and become protagonists in significant architectural spaces. The students are actively involved during inspections and studio visits, making drawings and sketches, taking measurements and photos. They collaborate, they exchange thoughts and opinions, asking for more information and posing problematic questions that involve the essence of living, constructing, composing. Questions that rarely emerge when they attend passive teacher-led classroom lessons with projections of images and designs in dimly-lit rooms.

In terms of the quality of teaching we must always remember that university education represents an impassioned decision to learn more and expand our knowledge; it isn't mandatory, it isn't a place of coercion because university isn't just about studying, it is also culture, sport, art, vision and sharing ideas. In this regard the Bauhaus was a pioneer and remains fascinating to this day because of the innovative concept of teaching it adopted, centred on the close connection between practical activities and theory. The blend of anti-academic intellectual positions, unconventional teachings and the mythical emancipation of women saw the Bauhaus school adopt a radically new and modern vision of everyday life. New forms of civil life, the experience of a new perception of the corporal sphere, the role of music in the school and its imaginative parties were all examples of its close affinity with the spirit of the time, L'Esprit Nouveau, and its continuous and vibrant commitment to truly multidisciplinary experimentation.

As such, I believe that among the hidden layers of the contemporary school we can find the real meaning of the Roman scholè, a place where a love of knowledge thrives through study and theoretical research, and also rediscover the sphere of practice, observation and experience. In my opinion the abstraction of (too) many educational experiences from real life in architectural design severely limits our ability to learn from the teaching provided over time. The Campus space on one hand, as the main site of students' everyday experience, and Lecturers on the other are the first elements through which to update our universities: the hypothesis of an open campus, of informal spaces, of unconventional or alternative physical-spatial and pedagogical courses, together with the radical updating of teaching methods, represent the tools for pursuing higher quality architectural training. The hypothesis of opening and adjusting the boundaries that codify the forms of coexistence on the campus or the school premises makes it possible to reclassify school spaces with open and 
permeable public spaces. At the same time these could become key structures for giving form to the space inhabited by human beings in their individual or social dimensions. The focus of my research is the updating of the spatial figures of learning in the knowledge that the distance between current and future public schools will be drastically reduced with new methods of active learning and coexistence, through inclusion and sharing strategies, through actions capable of addressing and mending the fractures, contradictions and problems that characterise them.

\section{PROJECT ACTIONS IN THREE CASE STUDIES}

In parallel with the promotion of didactic innovation processes and the development of policies for the internationalisation of universities, the urban and architectural regeneration of school spaces has assumed a central role in all socio-educational contexts that intend to embrace the rapid changes of recent decades. Below I will analyse the processes of regeneration and adjusting to the new conditions in three case studies (Milan Polytechnic, Bocconi University of Milan, department research study "A shared school"), which specifically involve the up-dating of the spatial figures of learning.

\section{Milan Polytechnic}

Milan Polytechnic has invested lots of resources in creating a more welcoming, forward-looking university. As well as constructing various student houses from scratch and improving existing buildings, in 2017 it opened a worksite to redevelop the Bonardi Campus. "The development process around Via Bonardi that began in the post-war years created an overload of buildings without following a single project and resulted in an area notable for its poor environmental quality and lack of free spaces. Because of this the university launched a project to redevelop and reorganise the area in an attempt to improve the quality of the buildings and their functionality; the plan is to increase the number of open spaces and study areas available to students and to improve the quality of the environment through the creation of large green spaces. The new university campus stems from an idea by Renzo Piano given to Milan Polytechnic and from the enhancement and development of the original idea by Odb-Ottavio Di Blasi \& Partners"5. The project, currently in

5 https://www.polimi.it/en/the-politecnico/university-projects/construction-sites/ new-architecture-campus/ 
the works, is focused on the creation of two pedestrian axes that cross the campus, the first running from east to west from via Ampere to via Ponzio, and the second going from north to south from via Bonardi towards the centre of the campus. A new system of open and tree-lined common spaces connects the ground level of the city with the campus's wood 3.5 metres below street level. The project on via Bonardi involves the development of a new low building, for classrooms and labs, whose roof is designed as a public square at ground level. From this new urban space it will be possible to see the crowns of the trees in the university area. A project centred on the two sections which generate a new relationship between the existing volumes thanks to the redevelopment of the open space which from a car park is transformed into a tree-lined connecting space for students, a place for informal socialisation, leisure and recreation.

At the same time Milan Polytechnic is seeking to modernise in the area of educational innovation with the aim of providing its professors and researchers with a specific pedagogical background that integrates traditional teacher-led approaches with processes in which the students play an active role. ${ }^{6}$ The goal is to stimulate active learning, involving students in the solving of real problems, fostering their creative potential and development of soft skills also through the appropriate use of digital tools and content. "The role of education systems is no longer that of replicating existing social systems but of creating the necessary conditions for the invention of new worlds. Can the fact that students are not what they used to be constitute an alibi? Perhaps not. We adults have also changed over time and even the world is not how it once was. In the world in which we live, if education is not profoundly reshaped in terms of its goals and methods it could, as Davidoff argues, become a tool for forming the most effective vandals on earth. And perhaps we can no longer afford to run this risk. Goals and the means of achieving them take form reciprocally. This is the same in all human contexts and also in the field of education. If we propose to rethink the goals of education, we must also reflect seriously on its methods and styles." (S. Sancassani, 2019). On this premise, planning and introducing educational innovations means posing ourselves the problem of moving from a teacher-led and transmissive approach to one in which learning processes are centred on the student. Processes that stimulate their active, creative and collaborative dimensions are the cornerstones of the learning experience at a time of 
rapid evolution and substantial change. To find solutions that are not simply a replica of those identified in the past, the key competences are those defined by the 4 C's: collaboration, creativity, communication and critical thought. Competences that make it possible to lean on specialist knowledge and skills when faced with new problems. Through a process that brings soft skills into play, the improvement of the learning experience must extend as far as the scope of the architectural design discipline: a collaborative group effort that stimulates creativity but at the same time creates a solid basis of scientific knowledge and humanist cultural components which together are able to drive informed critical thinking.

\section{Bocconi University}

The Bocconi University case is emblematic for the gradual and pervasive development process which has continued unabated around its historic site since it was founded in 1902. The main milestones are summarised in order to emphasise the periodic need for the change, adaptation and extension of its spatial configurations.

The rationalist building of Giuseppe Pagano and Gian Giacomo Predeval, opened in 1941, was designed according to an open but rigorous plan; it was flanked in 1956 by a building that hosted the canteens and the student residences, designed by Giovanni Muzio. After the further extension of the Aula Magna and the library with a number of departments in the 1960s (Giovanni Muzio 1963), the next development took place in the 1980s when a rooftop extension and some additions to the existing volumes created new surfaces. Designed by Ignazio Gardella, an elliptical building known as "the velodrome" and containing new classrooms was opened to the north of the Campus on via Sarfatti in 2001. The subsequent project of Grafton Architects (2003-2008), carried out following an international call for tenders, marked an important and decisive moment in the redesign and radical transformation of the university's spaces: the vigorous new volumes clad in Ceppo Lombardo stone and the large window of the underground Auditorium on Viale Bligny create a modern monument that refreshes the identity of Bocconi University. The internal courtyards, open to the public as well as citizens, are accessible new urban spaces. The main public square has become an active and established part of the city, giving the Campus an interesting new urban boundary that is innovative but at the same time strong, tactile and authoritative.

Another development characterising the ever-changing and dynamic Bocconi University Campus is an expansion to 
the south that incorporates the former area of the Centrale del Latte, an abandoned site that hosted the municipal milk collection and processing factory that served the entire city of Milan. The project by international architecture firm SANAA belonging to Kazuyo Sejima and Ryue Nishizawa involves close interaction with the surrounding urban fabric. The green and connecting system will involve the existing Parco Ravizza and the cycle/pedestrian path will open up the sports and leisure centre with gyms and Olympic-size swimming pool to the city. ${ }^{7}$ The sinuous forms of the new campus that will emerge from the connecting open spaces and greenery of the park will host new residences for students, new spaces for teaching and offices, resulting in a modern campus layout that is innovative on the international panorama and at the same time attentive to local requirements.

\section{"A shared school for a culture of happiness", a research study}

My third case study on the modernisation of the spatial figures of learning relates to the project I am carrying out at the Department of Architecture and Urban Studies at Milan Polytechnic. Covering architecture, pedagogy and social action, the research study entitled " $A$ shared school, for a culture of Happiness" focuses on the innovation of teaching and on rethinking the role of the public education institution for schools, in the age range of 5 to 14 years. $^{8}$

Based on the observation that the public school education model is no longer able to meet the social needs of the modern world the Government, through the 2016 Stability Law and in cooperation with banking foundations, set up a fund to combat child educational poverty in order to support experimental measures to remove the cultural, social and economic barriers that prevent minors from fully accessing educational processes.

The primary goal of the partnership set up for the "A shared

7 Bocconi University, new Campus in Milan: https://www.unibocconi.eu/wps/wcm/ connect/bocconi/sitopubblico_en/navigation+tree/home/campus+and+services/ bocconi+urban+campus/new+campus

8 The "A shared school for culture of Happiness" project was the winner of the Nuove Generazioni 2017 competition [https://www.conibambini.org/bando-nuove-generazioni-5-14-anni], a Fund for combating child educational poverty. Project leaders Cooperho and the La Fucina association with the Municipality of Rho. Scientific Committee: Prof. Monica Guerra, Prof. Francesca Antonacci of the Department of Human Sciences for Education, Bicocca University Milan; Prof. Barbara Coppetti for DAStU — Department of Architecture and Urban Studies, Milan Polytechnic; Barbara Mitelli, Marina Alini for the Humanistic Coaching School of Milan. 
school" project is to stop the gradual educational impoverishment identified by the school's stakeholders.

From a pedagogical perspective the project aims to trial and export an action model that makes it possible to affect important changes in the sphere of public schools. These must be able to modernise in order to meet the need for change imposed by modern society without losing their educational mandate as a place for the learning and growth of every individual. In fact, the school environment continues to symbolise the key institution of learning for families and a reference point in the daily lives of children. Their belonging to complex cultural and social contexts, not just related to their geographical origins but also connected with their age, social class, habits and ways of dealing with emotions, is certainly one of the reasons for the inadequacy of the responses of modern schools.

The inability to manage different habits, reactions and emotions connected with structurally distant roots leads to dissatisfaction and the impoverishment of the educational and development action of schools. In addition, the organisation of public schools is regulated by structures and resources that must be supported in such a way that the transformation foreseen at various levels (EU, Ministry of Education, University and Research, local authorities) is both real and positive. The new educational project proposed in the study introduces a method of learning that involves the entire being (mind, body, emotions) and enables relatives to identify hidden talents and abilities. "A shared school" therefore favours the model of an open and common school, a democratic place for growth, meeting, exchange and enrichment where children can experience sensory relations.

In parallel, from an architectural and spatial perspective, the school will be redesigned in qualitative terms through a project to redevelop collective spaces and modernise the identity of the places. A spatial modernisation project to be realised via minimal actions, measured against the sense of belonging to the school of the children, the teachers, parents - in other words, the entire educational community.

The aim is to redefine the sense of recognition between the school and all those who frequent it: an architectural project that gives new identity to the spaces, offering new interdisciplinary perspectives in places where critical social issues, marginalisation and sometimes even violence seem to prevail.

By looking after the premises, taking care of school spaces like the garden, the trees, the play area, the canteen and all reception areas, it will be possible to reconfigure areas often viewed as weak and marginal. The project also aims at reflecting on the technical components of health, safety and energy efficiency of the school building. 
In the "A shared school" project the modernisation of the identity of the public school simultaneously involves both the pedagogical/didactic and architectural and spatial aspects, but it is also important to work in tandem with local voluntary associations. The complex and indispensable network that has been formed, together with the municipal council of Rho, local businesses, neighbourhoods and groups operating in the local area to raise awareness of specific cases, is generating an interesting joint venture experiment. The three schools that have signed up for the project form part of the two Franceschini and Anne Frank Istituti Comprensivi and are holding the first meetings to identify the classes and teachers which, on a voluntary basis, will actively take part in the joint architectural design activities, workshops and humanistic coaching sessions. In the fertile and vibrant test bed of the Franceschini Medaglie d'Oro school we have already launched the collaboration and joint design process relative to the modifications that the students and educational community would like to make to their school and the adjacent public park.

\section{TAKING CARE OF PLACES AND TAKING CARE OF PEOPLE}

The updating of the spatial figures of learning and the aim of the research the group is conducting involve the redesign of existing apparatus. Adapting and opening the doors and the fences of schools with inclusion and sharing strategies, with actions that address and treat the fractures, contradictions and problems that characterise them, can certainly reduce the distance between present and future public schools. The hypothesis of opening and adjusting aspects like the boundaries of the school, which traditionally regulate methods of coexistence, can redefine the spaces through new permeable connections. In parallel with trialling new ways of learning and living together, the notion of opening the school premises to the neighbourhood, to intergenerational cultural, recreational and educational daytime and evening activities would certainly make the school a recognisable and vibrant hub. Dedicating time to discovering the specific skills of each person and reserving space for the individual in relation to the group are key objectives of the Shared School architectural and pedagogical project.

The project for the redevelopment and care of the spaces of state schools that is being developed, together with the other phenomena taking place not just in Italy but all over Europe in the area of university education, necessarily focus renewed attention on the emancipation of every individual who, regardless of their origins or age, must strive for self-satisfaction and self-fulfilment. 
This can happen through education and the management of one's emotions, gradually leading to independence, and through the culture of happiness experienced by those who achieve complete self-fulfilment. An aspect that follows on from the ancient idea of human learning implied in the Greek Paidéia, where the complete formation of the individual came about by studying the disciplines guarded by the Muses: poetry, art, music, history, comedy, tragedy and dance. Mythical figures that embody a specific idea of harmonious integration in society, reflection of the supreme ideal of civil society where sensitivity and emotions have time, space and ways to express themselves.

\section{BIBLIOGRAPHY}

Antonacci, F., Guerra M., eds. (2018). Una scuola possibile. Studi ed esperienze intorno al Manifesto «Una scuola», Franco Angeli

Bandura, A. (1977).Social Learning Theory. New York: General Learning Press.

Cantarella, E., Guidorizzi G. (2015). Il lungo presente. Da Augusto all'anno Mille, il mondo globale e i continenti. Edizioni Einaudi Scuola.

Fiedler, J., Feierabend P. , eds (2000). Bauhaus, Konemann Germany 1999/ Studio Associato Buysschaert \& Malerba, Milan 2000

Gagné, R. M. (1965). The Conditions of Learning. New York: Holt, Rinehart \& Winston.

Galimberti, U. (2010). Educare l'anima ai tempi della tecnica ('Educating the soul in the times of technique') Full speech, May 2010, Muro Leccese. Event organised by II teatro della Busacca. Audiovisual documentation by ACMElab - www. acmelab.it

Galimberti, U. (2018). The degeneration of the school, Messora C., Byoblu, 20 April 2018 [https://www.byoblu.com/2018/04/20/ la-degenerazione-della-scuola-umberto-galimberti]

Sancassani, S., Brambilla F., Casiraghi D., Marenghi P. (2019). Progettare l'Innovazione Didattica, Pearson

Tenuta, U. (2013). Scuola, Scholè, Otium. Tempo libero, studio, amore del sapere, filosofia. [http://www.edscuola.eu/wordpress/?p=34688]

Weyland, B., Attia S. (2015). Progettare scuole tra pedagogia e architettura. Guerini e Associati Milano 


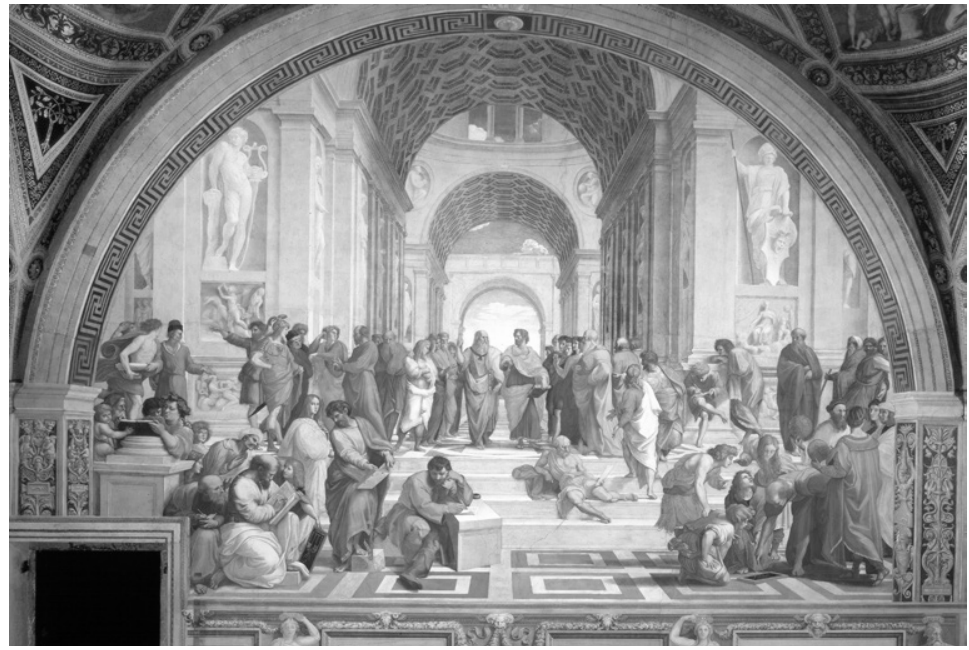

Fig. 1: The School of Athens by Raphael, 1509-1511, fresco in Stanza della Segnatura, Vatican Museum, Vatican, Rome

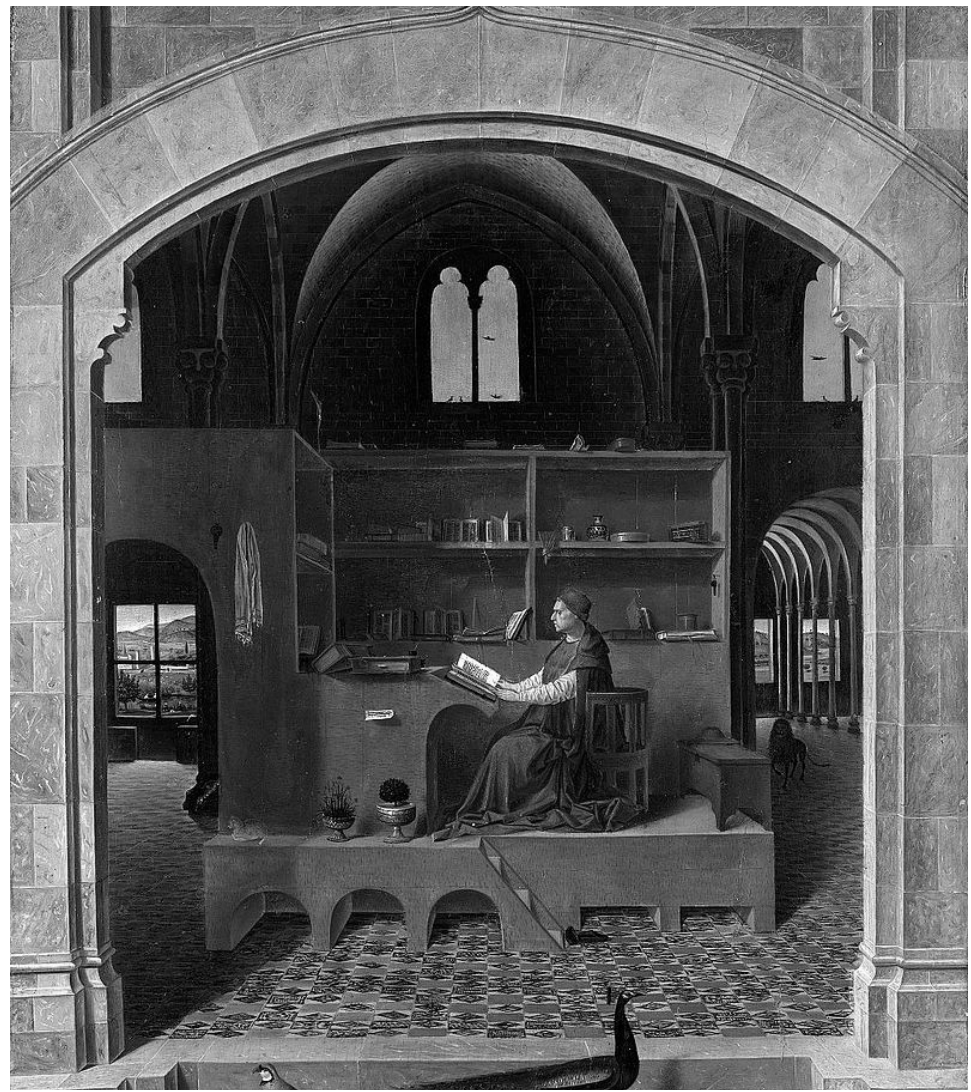

Fig. 2: St. Jerome in his study by Antonello da Messina, 1474-1475, painting conserved at the National Gallery of London 


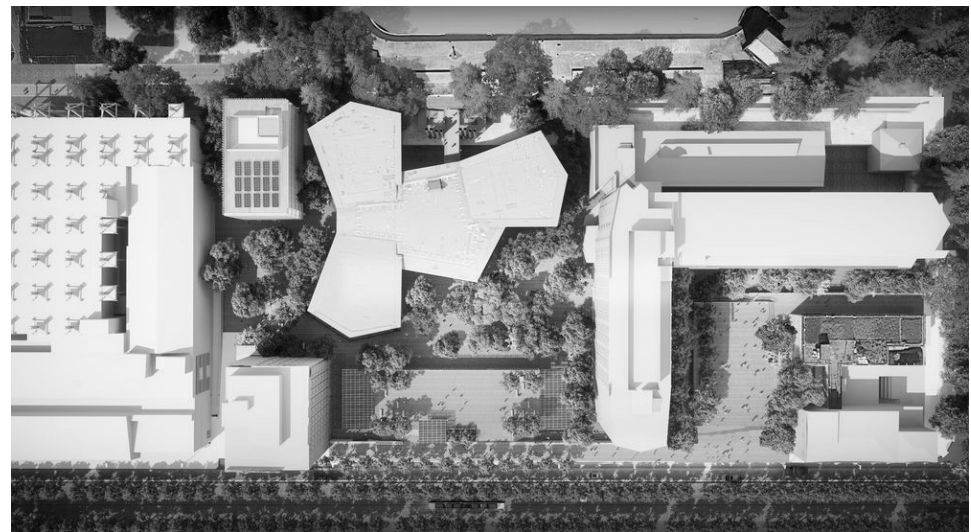

Fig. 3: The urban value of the new Bonardi Campus at Milan Polytechnic: from Giò Ponti, Piero Portaluppi, Giordano Forti Project (1953-61) to the Vittoriano Viganò Building (1970-85) to the new pedestrian path between the trees designed by Renzo Piano, (2015).

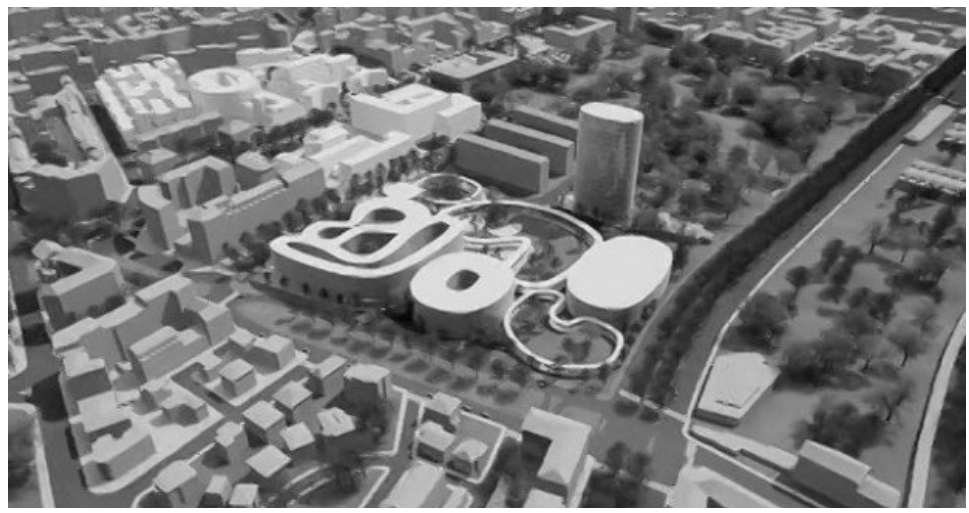

Fig. 4: The urban value of the new Bocconi Campus in Milan. Grafton Architects (2003-2008) on Viale Bligny and SANAA 2015: the University is expanding to the south, incorporating the former area of the Centrale del Latte (former milk collection and processing plant for the entire municipality of Milan). The striking forms of the new campus will revitalize and interact with the surrounding urban fabric.

\section{IMAGE SOURCES}

Fig. 1 The School of Athens' by Raffaello Sanzio, 1509-1511, fresco in Musei Vaticani, Rome

Fig. 2 St Jerome in his study by Antonello da Messina, 1474-1475, painting in National Gallery London

Fig. 3 The urban value of new Campus Bonardi in Polytechnic University of Milan

Fig. 4 The urban value of new Bocconi Campus in Milano 